\title{
Analisis radiograf periapikal menggunakan software Image J pada granuloma periapikal pada perawatan endodontik
}

\author{
Ali Thomas*, Ria Noerianingsih Firman**, A. Azhari** \\ *Program Pendidikan Dokter Gigi Spesialis, Program Studi Radiologi, Kedokteran Gigi, Fakultas Kedokteran Gigi, \\ Universitas Padjadjaran, Bandung, Jawa Barat, Indonesia \\ **Departemen Radiologi Dentomaksilofasial, Fakultas Kedokteran Gigi, Universitas Padjadjaran, Bandung, Jawa Barat, Indonesia \\ *JI Sekeloa Selatan No 1, Bandung, Jawa Barat, Indonesia; e-mail: alithomas_1978@yahoo.com
}

Submisi: 29 Maret 2016; Penerimaan: 9 Oktober 2016; Publikasi online: 31 Agustus 2017

\begin{abstract}
ABSTRAK
Penilaian tingkat keberhasilan perawatan endodontik pada gigi yang mengalami granuloma periapikal, saat ini masih menggunakan metoda konvensional yaitu dengan menggunakan viewer sebagai alat bantu dan diinterpretasi secara subjektif oleh dokter gigi. Keadaan ini mengakibatkan peluang terjadinya perbedaan penilaian cukup besar secara inter dan intra-observer. Tujuan dari penelitian ini adalah untuk mengetahui perbedaan gambaran dan hubungan nilai luas lesi, jumlah dan luas partikel trabekula pada kasus granuloma periapikal sebelum dan sesudah perawatan endodontik melalui digitalisasi radiograf periapikal menggunakan software ImageJ. Penelitian ini dilakukan dengan menggunakan metode analisis observasional. Sampel yang digunakan dalam penelitian ini terdiri dari 30 data sebelum perawatan endodontik dan 30 data sesudah perawatan endodontik yang telah dilakukan digitalisasi. Hasil penelitian ini adalah terjadi penurunan rata-rata luas lesi granuloma periapikal dari $16.400 \pm 2.2924 \mathrm{~mm}^{2}$ menjadi $13.860 \pm 2.1250 \mathrm{~mm}^{2}$, peningkatan rata-rata jumlah partikel dari $70.167 \pm 7.2258$ menjadi $99.733 \pm 7.4089$ dan peningkatan luas partikel dari $14.033 \pm 1.4452 \mathrm{~mm}^{2}$ menjadi $19.017 \pm 1.4223 \mathrm{~mm}^{2}$. Simpulan dari penelitian ini adalah terdapat perbedaan gambaran dan hubungan nilai luas lesi, jumlah dan luas partikel trabekula pada kasus granuloma periapikal sebelum dan sesudah perawatan endodontik melalui digitalisasi radiograf periapikal menggunakan software ImageJ.
\end{abstract}

Kata kunci: digitalisasi radiograf periapikal; granuloma periapikal; software ImageJ

\begin{abstract}
Analysis of periapical radiographs using ImageJ software on periapical granuloma in endodontic treatment. The assessment of the success rate of endodontic treatment on teeth with periapical granuloma is currently still using the conventional method, that is using a viewer as the tool which is then interpreted subjectively by dentist. This may lead to the possibility of significant differences in the assessment between inter and intra-observers. The objective of this study was to demonstrate the differences in picture and the relationship of lesion size, and the number and size of trabecular particles on periapical granuloma cases before and after endodontic treatment with digitized periapical radiographs using ImageJ software. This study was conducted using observational analysis method. The sample in this study consisted of 30 data before endodontic treatment and 30 data after endodontic treatment that had been digitized. The results of this study showed a decrease in the average size of periapical granuloma lesions from 16,400 $\pm 2.2924 \mathrm{~mm}^{2}$ to $13.860 \pm 2.1250 \mathrm{~mm}^{2}$, an increase in the average number of particles from $70.167 \pm 7.2258$ to 99.733 \pm 7.4089 and an increase in the particle size from $14.033 \pm 1.4452 \mathrm{~mm}^{2}$ to $19.017 \pm 1.4223 \mathrm{~mm}^{2}$. The conclusion of this study is that there are different pictures and relationship between the size of lesions, the number and size of trabecular particles in periapical granuloma cases before and after endodontic treatment through digitized periapical radiographs using ImageJ software.
\end{abstract}

Keywords: digitized periapical radiographs; periapical granuloma; ImageJ software

\section{PENDAHULUAN}

Penilaian tingkat keberhasilan perawatan endodontik pada gigi yang mengalami granuloma periapikal saat ini masih menggunakan metode konvensional yaitu dengan menggunakan viewer sebagai alat bantu dan diinterpretasi secara subjektif oleh dokter gigi. Keadaan ini mengakibatkan peluang terjadinya perbedaan penilaian cukup besar secara inter maupun intra observer yang menurut suyambukesan et.al (2013) hanya $79,6 \%$ terjadi kekonsistenan interpretasi secara intraobserver. $^{1}$

Parameter kemajuan hasil perawatan adalah apabila terjadi pemadatan tulang di daerah lesi. Beberapa penelitian telah dilakukan untuk melihat gambaran trabekula melalui radiograf berdasarkan 
pola trabekula. Jie Yang (2012) menyatakan bahwa pola trabekula berkorelasi baik dengan DXAsebagai standar baku penentuan kualitas tulang. ${ }^{2}$ Analisis pola trabekula telah berkembang dengan berbagai macam metoda menggunakan berbagai filter untuk menghilangkan noise sehingga diharapkan mendekati kepadatan sebenarnya dari trabekula. Salah satu software yang banyak digunakan dalam penelitian menggunakan image processing saat ini adalah software Image $J$ yang memiliki menu untuk image, process dan analyze serta berbagai fitur untuk menganalisis partikel, thresholding dan histogram statistik. Software ini mampu mengukur luas lesi serta jumlah partikel dan luas partikel trabekula tulang. ${ }^{3}$ Penelitian yang dilakukan oleh Sogur et.al (2013) menyatakan bahwa pada lesi periapikal terjadi peningkatan demineralisasi yang menyebabkan fraktal dimensi berkurang. ${ }^{4}$

Perawatan endodontik berfungsi untuk menghilangkan iritan berupa debris dan bakteri dalam saluran akar melalui tahap cleaning and shaping, sterilisasi, dan obturasi. Penggunaan bahan-bahan irigasi, sterilisasi dan pengisi yang bertindak sebagai bakterisid mengakibatkan penurunan aktivitas bakteri dan penonaktifan mediator inflamatory. Perawatan endodontik mengaktivasi regenerasi dan kalsifikasi trabekula yang merupakan indikator proses regenerasi. ${ }^{5}$ Pembentukan tulang baru berjalan dari perifer ke pusat lesi, pertama diawali dengan pembentukkan osteoblas atau mesenkimal yang melapisi jaringan endosteum mengalami proliferasi dan diferensiasi menjadi osteoblas dan menghasilkan matriks tulang.

Secara radiografi, granuloma periapikal mempunyai gambaran lesi radiolusen kecil yang berbatas jelas dan dapat didiagnosis banding dengan kista periapikal. Namun, hal yang membedakan kista dan granuloma adalah dari ukuran kista yang lebih besar melebihi $1 \mathrm{~cm}$, adanya pergeseran struktur disekitarnya serta ekspansi batas terluar dari korteks tulang rahang. ${ }^{5}$

Gambaran radiolusen pada granuloma periapikal menunjukkan terjadinya destruksi sesudah dilakukan perawatan endodontik, penambahan matriks tulang dan fibrous akan mengubah tingkat kepadatan dengan meningkatkan absorbsi sinar $\mathrm{X}$.
Keadaan ini akan berdampak terhadap lapisan film $(\mathrm{AgBr})$ yang dipengaruhi oleh kepadatan matriks trabekula. Gambaran perubahan kepadatan trabekula dapat terlihat dengan melakukan preprocessing pada radiograf. ${ }^{3}$ Preprocessing dilakukan secara komputerisasi dengan menggunakan filter pada software ImageJ. Dalam preprocessing dilakukan filtering dan untuk menghitung luas dilakukan biner, sehingga didapatkan gambaran putih sebagai jaringan padat dan hitam untuk jaringan lunak. Berdasarkan latar belakang yang telah diuraikan di atas, peneliti ingin mengetahui apakah terdapat perbedaan gambaran dan hubungan antara nilai luas lesi, jumlah dan luas partikel trabekula pada granuloma periapikal sebelum dan sesudah perawatan endodontik melalui digitalisasi radiograf periapikal menggunakan software ImageJ.

\section{METODE PENELITIAN}

Penelitian ini dilakukan dengan menggunakan metode analisis observasional. Penelitian ini menggunakan data sekunder radiograf periapikal pada suspek granuloma periapikal di RSGM Unpad Bandung periode Januari-Desember 2015 dengan teknik pengambilan sampel consecutive sampling. Penelitian dimulai pada bulan Desember 2015. Sampel yang digunakan dalam penelitian ini berjumlah 60 radiograf (30 sebelum perawatan dan 30 setelah perawatan). Penelitian ini telah mendapatkan persetujuan dari Komite Etik Fakultas Kedokteran Universitas Padjadjaran Bandung, dengan nomor 019/UN6.C1.3.2/KEPK/PN/2016.

Data yang terkumpul kemudian discan dan dikelompokkan menjadi sebelum dan sesudah perawatan endodontik. Gambar hasil scan dilakukan cropping dan disimpan sebagai Gambar 1. Ukur luas lesi radiolusen menggunakan fitur threshold dan didapat luas lesi dalam $\mathrm{mm}^{2}$. Cara menghitung jumlah dan luas partikel dilakukan dengan filtering Gaussian Blur, masukkan angka 3, kemudian disimpan sebagai Gambar 2. Selanjutnya dilakukan substract dan multiply, kemudian masukkan nilai add 128. Ubah gambar menjadi biner dan hilangkan noise dari gambar dengan melakukan erode dan dilate masing-masing 3 kali. Ubah gambar menjadi outline dan hitung jumlah dan luas partikel. 

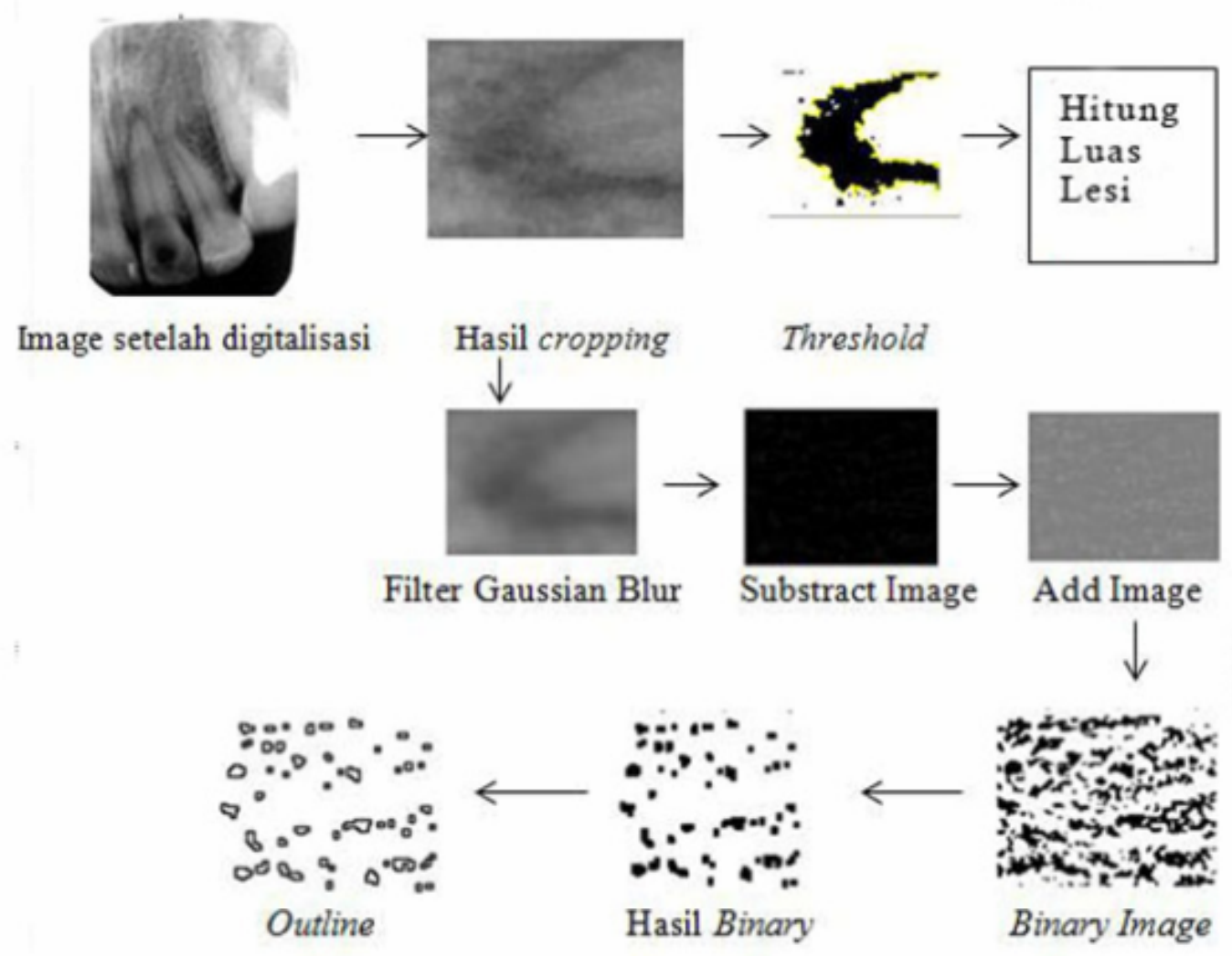

Gambar 1. Cara pengukuran luas lesi, serta jumlah dan luas partikel menggunakan software ImageJ

Hasil dideskripsikan dalam tabel dari masingmasing variabel, dan dilakukanujistatistikuntukmelihat perbedaan antara luas area lesi, jumlah partikel serta luas partikel pada lesi granuloma periapikal sebelum dan sesudah dilakukan perawatan endodontik. Data yang didapatkan berupa data numerik, sehingga uji statistik yang digunakan adalah uji t-independent. Dari hasil tersebut kemudian dilakukan uji korelasi untuk melihat besarnya pengaruh dari tiap variabel menggunakan uji regresi linier berganda.

\section{HASIL PENELITIAN}

Hasil pengukuran luas lesi granuloma periapikal sebelum dan sesudah perawatan endodontik pada radiograf periapikal yang telah didigitalisasi dengan jumlah sampel masing-masing kelompok sebanyak 30 buah dapat dilihat pada Tabel.

Berdasarkan Tabel 1, nilai rata-rata luas lesi sebelum perawatan endodontik adalah $\quad 16,40$ $\pm 2,29 \mathrm{~mm}^{2}$ dan sesudah perawatan 13,86 $\pm 2,12$ $\mathrm{mm}^{2}$. Penurunan luas lesi sesudah dilakukan perawatan endodontik rata-rata sebesar $15,63 \%$, dengan persentase terbesar mencapai $21,31 \%$ dan yang terkecil $10,67 \%$. Berdasarkan uji t-independent terdapat perbedaan signifikan antara luas lesi granuloma periapikal sebelum perawatan endodontik dengan luas lesi sesudah perawatan endodontik.

Berdasarkan Tabel 2, nilai rata-rata jumlah partikel lesi sebelum perawatan endodontik adalah $70,16 \pm 7,22$ dan sesudah perawatan 99,73 \pm 7,40 . Kenaikan jumlah partikel sesudah dilakukan perawatan endodontik rata-rata sebesar $42,75 \%$, dengan persentase terbesar mencapai $65,00 \%$ dan yang terkecil $27,16 \%$. Berdasarkan uji t-independent terdapat perbedaan signifikan antara jumlah partikel sebelum perawatan endodontik dengan jumlah partikel sesudah perawatan endodontik.

Berdasarkan Tabel 3, nilai rata-rata luas partikel lesi sebelum perawatan endodontik adalah $14,03 \pm 1,44 \mathrm{~mm}^{2}$ dan sesudah perawatan 19,01 $\pm 1,42 \mathrm{~mm}^{2}$. Kenaikan luas partikel sesudah dilakukan perawatan endodontik rata-rata sebesar $35,89 \%$, dengan persentase terbesar mencapai $45,00 \%$ dan yang terkecil $28,57 \%$. Berdasarkan uji t-independent terdapat perbedaan signifikan antara 
Majalah Kedokteran Gigi Indonesia. Agustus 2017; 3(2): 105 - 110

ISSN 2460-0164 (print)

ISSN 2442-2576 (online)

Tabel 1. Luas lesi granuloma periapikal sebelum dan sesudah perawatan endodontik

\begin{tabular}{cccc}
\hline \multirow{2}{*}{$\begin{array}{c}\text { Jumlah Radiograf } \\
\text { (Pasang) }\end{array}$} & Sebelum & Luas Lesi $\left(\mathrm{mm}^{2}\right)$ \\
\cline { 2 - 4 } & $16,40 \pm 2,29$ & $13,86 \pm 2,12$ & Persentase \\
\hline 30 & & & 15,63 \\
\hline
\end{tabular}

Tabel 2. Jumlah partikel lesi granuloma periapikal sebelum dan sesudah perawatan endodontik

\begin{tabular}{cccc}
\hline \multirow{2}{*}{$\begin{array}{c}\text { Jumlah Radiograf } \\
\text { (Pasang) }\end{array}$} & Sebelum & Jumlah Partikel (buah) \\
\cline { 2 - 4 } & $70,16 \pm 7,22$ & Sesudah & Persentase \\
\hline 30 & & $99,73 \pm 7,40$ & 42,75 \\
\hline
\end{tabular}

Tabel 3. Luas partikel lesi granuloma periapikal sebelum dan sesudah perawatan endodontik

\begin{tabular}{cccc}
\hline \multirow{2}{*}{$\begin{array}{c}\text { Jumlah Radiograf } \\
\text { (Pasang) }\end{array}$} & \multicolumn{3}{c}{ Luas Partikel $\left(\mathrm{mm}^{2}\right)$} \\
\cline { 2 - 4 } & Sebelum & Sesudah & Persentase \\
\hline 30 & $14,03 \pm 1,44$ & $19,01 \pm 1,42$ & 35,89 \\
\hline
\end{tabular}

luas partikel sebelum perawatan endodontik dengan luas partikel sesudah perawatan endodontik.

\section{PEMBAHASAN}

Luas lesi granuloma periapikal mengalami penurunan sesudah dilakukan perawatan endodontik sebesar $15,63 \%$. Jaringan granulasi pada granuloma periapikal mengakibatkan berkurangnya penyerapan foton sinar $X$ yang mengakibatkan gambaran radiolusen pada film. ${ }^{6,7,8,9}$ Proses penyembuhan lesi periapikal terjadi melalui peningkatan vaskularisasi, pembentukan fibroblas, sementum seluler dan pengaktifan osteoblas. ${ }^{5}$ Keadaan ini mengarah pada proses pembentukan tulang trabekula dari endoseus, dimana osteoblas dan sel mesenchymal berpoliferasi menjadi osteoblast dan membentuk matriks tulang yang lebih padat dari jaringan granulasi. ${ }^{10}$ Peningkatan kepadatan di area lesi akan meningkatkan penyerapan foton sinar $X$, sehingga akan menghalangi sinar $X$ mengenai kristal sensitif pada film dan akan tampak gambaran radioopak. ${ }^{6,8,9}$

Penurunan luas lesi granuloma periapikal terlihat sesudah dilakukan perawatan endodontik. Estrela dan Figueiredo (1999) menemukan bahwa pemeriksaan klinis dan radiografi yang dievaluasi sesudah periode lebih dari dua tahun mampu memberikan hasil perawatan yang optimal. ${ }^{11}$ Jika lesi ukurannya membesar atau tidak berubah sesudah satu tahun perawatan, dapat dikatakan perawatan endodontik yang dilakukan telah gagal. ${ }^{12}$
Untuk menentukan luas lesi secara computerized, gambaran radiograf digitalisasi memberikan nilai berbeda-beda pada setiap pixelnya, dan dengan proses thresholding dapat dipisahkan antara area lesi dan jaringan sekitarnya. ${ }^{13}$ Pengukuran jumlah partikel menunjukkan terjadinya peningkatan jumlah partikel pada radiograf sesudah perawatan endodontik sebesar $42,75 \%$. Jumlah partikel merupakan gambaran partikel yang mempunyai dentitas yang jumlahnya meningkat sesudah dilakukan perawatan endodontik. Keadaan ini menunjukkan bahwa sudah terjadi pengurangan jaringan granulasi maka proses remineraliassi dimulai. Secara analisis digital, perubahan nilai pixel terjadi pada daerah yang awalnya tidak menyerap foton menjadi menyerap foton sinar $X$ yang tinggi. Pixel-pixel tersebut dipisahkan dengan mengubahnya menjadi citra biner, sehingga pixel yang rendah dihilangkan sedangkan pixel yang tinggi ditampilkan. ${ }^{14}$

Jumlah luas partikel trabekula pada lesi granuloma periapikal sesudah perawatan endodontik menunjukan adanya kenaikan. Hal ini menunjukkan banyak tulang trabekula baru dan sesuai dengan penelitian Carnerio et.al (2009) yang menunjukkan penurunan angka periapical index pada CBCT. Jumlah luas partikel trabekula merupakan jumlah dari seluruh luas partikel-partikel yang berada dalam daerah penelitian.

Berdasarkan hasil uji korelasi, hubungan semakin kecil luas lesi, semakin banyak jumlah 
partikel trabekula dan semakin luas partikel trabekula Penelitian yang dilakukan oleh Amer (2011) menyatakan bahwa peningkatan jumlah partikel memiliki korelasi dengan peningkatan luas partikel sehingga jumlah dan luas partikel memiliki pengaruh terhadap luas lesi. Besaran jumlah dan luas partikel berbanding terbalik dengan luas lesi. Pada penelitian ini idapatkan besarnya pengaruh jumlah partikel dan jumlah luas partikel sebesar $29,8 \%$, sedangkan sebesar $70,2 \%$ dipengaruhi oleh faktor-faktor lainnya.

Teixeira (2010), menyatakan bahwa resorpsi tulang periapikal kecil pun sudah cukup untuk menentukan perubahan nilai pixel dari daerah lesi periapikal dengan metode digital langsung. ${ }^{15}$ Saeed et.al (2014) juga menegaskan bahwa variasi dalam nilai skala abu-abu pada lesi periapikal bila dihubungkan dengan perubahan histologis, mempunyai korelasi langsung antara nilai dan jenis bahan di dalam lesi. Hasil ini konsisten dengan yang disampaikan oleh Camps dkk. (2004). ${ }^{16,17}$ Penelitian ini memiliki hasil yang sesuai dengan penelitian Sogur et.al (2013), Chen dan Chen (2008) dan Yasar dan Akgunlu (2005) yang mengatakan bahwa pada lesi periapikal terjadi peningkatan demineralisasi yang menyebabkan fraktal dimensi berkurang. ${ }^{18}$

Sampel radiograf yang digunakan pada penelitian ini mempunyai jangka waktu perawatan rata-rata kurang dari 6 bulan, sehingga tidak didapatkan sampel sesudah perawatan endodontik yang mengalami penyembuhan secara sempurna, namun dapat dikatakan bahwa hasil perawatan endodontik yang telah dilakukan telah mengalami kemajuan, yang ditandai dengan penurunan luas lesi, peningkatan jumlah partikel dan luas partikel trabekula. Perbedaan hasil penelitian ini dengan penelitian lainnya dapat disebabkan oleh waktu pengambilan sampel, variasi anatomi, perbedaan teknik radiografi yang digunakan dalam pengambilan sampel, perbedaan ROI dan prosedur dalam mengukur dimensi fraktal. ${ }^{19}$

\section{KESIMPULAN}

Radiograf periapikal yang telah didigitalisasi mampu untuk mendeteksi secara dini perbaikan lesi yang terjadi sesudah dilakukan perawatan endodontik. Terdapat penurunan luas lesi yang dipengaruhi oleh kenaikan jumlah partikel dan luas partikel pada lesi granuloma periapikal melalui digitalisasi radiograf periapikal sesudah perawatan endodontik.

\section{DAFTAR PUSTAKA}

1. Suyambukesan S, Perumal G, Somasundaram E, Pandian NJ, Manigandan T. Analyzing periapical lesions on intraoral periapical radiographs: Incongruity on diagnosis. Journal of Indian Academy of Oral Medicine and Radiology. 2013; 25(1): 5 - 9.

2. Yang J, Pham SM, Crabbe DL. Effect of estrogen deficiency on rat mandibular and tibial microstructure. J Med Oral Patol. Oral Cir. Bucal. 2012; 17(4): $624-32$.

3. Carvalho FB, Gonçalves M, Tanomaru-Filho $M$. Evaluation of chronic periapical lesions by digital subtraction radiography by using Adobe Photoshop CS: A technical report. J Endod. 2007; 33: 493 - 497.

4. Sogur E, Baks BG, Grondahl HG, Hakan $S B$. Pixel intensity and fractal dimension of periapical lesions visually indiscernible in radiographs. J Endod. 2013; 39: 16 - 19.

5. Hargreaves KM, Cohen S. Cohen's pathways of the pulp. Edisi ke - 10. Missouri: Mosby; $2011.552-555,602-612$.

6. White P. Oral Radiology Principle and Interpretation. Edisi ke-7. Missouri: Mosby; 2014. 91 - 95, $314-318$.

7. Amer ME, Suk HM, Brooks SL, Beavides E. Anatomical variations of trabecular bone structure in intraoral radiographs using fractal and particles count analyses. Imaging Science in Dentistry. 2012; 42: 5-12.

8. Formmer $\mathrm{HH}$, Stabulas-Savage JJ. Radiology for the dental professional. Edisi ke - 9. St. Louis, Missouri: Elsevier; 2011; 37 - 65.

9. Whaites E, Drage N. Essentials of dental radiography and radiology. Edisi ke-5. Churchill Livingstone Elsevier; 2013. 45 - 47, $85-86$. 
10. Ingle JI, Bakland LK, Baumgartner JC. Ingle's Endodontics. Edisi ke-6. Ontario: BC Decker; 2008: 175 - 198.

11. MendozaAM, Jiménez CC, Linares Al, Mendoza BS, Yañez VRM. Endodontic treatment of large periapical lesions: An alternative to surgery. Edorium J Dent. 2015; 2: 1 - 6.

12. Razavi SM, Kiani S, Khalesi S. periapical lesions: a review of clinical, radiographic and histopathologic features. Avicenna J Dent Res. 2014; 6(1).

13. Carnerio LS, Nunes CA, Silva MA, Leles CR, Mendoca EF. In vivo study of pixel grey measurement in digital substraction radiography for monitoring caries remineralization. Dentomaxillofacial Radiology. 2009; 38: 73 - 78.

14. Angerame $D$, De Biasi $M$, Sossi $D$, Marigo L, Castagnola R, Somma F, Castaldo A. Periapical healing after simplified ebdodontics treatments: A digital substraction radiography study. Giornale Italiano di Endodonzia. 2013;
27: $74-79$.

15. Teixeira RC, Rubira CM, Assis GF, Lauris JR, Cestari TM, Rubira IR. Radiological and histopatological evaluation of experimentally induced periapical lesion in rats. Journal Application Oral Science. 2010. Melalui www. scielo.br/jaos (Diakses 9 Desember 2015)

16. Saeed SS, Ibraheem UM, Alnema MM. Quantitative analysis by pixel intensity and fractal dimensions for imaging diagnosis of periapical lesions. International Journal of Enhanced Research in Science Technology \& Engineering. 2014; 138 - 144.

17. Souto MF, Felipe SMB, Cury SE, Cury MP, Junqueira JC, Manhaes Jr LC. Atypical aggressive periapical granuloma: a case report. Webmed Central Oral Medicine. 2012; 3(1).

18. Sogur E, Baks BG, Grondahl HG, Hakan SB. Pixel intensity and fractal dimension of periapical lesions visually indiscernible in radiographs. J Endod. 2013; 39: 16 - 19.

19. Stauber $M$, Muller R. Age related changes in trabecularbone microstructure: global and lokacal morphometry. J osteoporosis international. 2005; (6): $10-25$. 